\title{
Abstract:
}

\section{Technology Transition a Model for Infusion and Commercialization}

The National Aeronautics and Space Administration (NASA) has, as part of its charter, the mission of transferring technologies developed for the space program into the private sector for the purpose of affording back to the American people the economical and improved quality of life's benefits associated with the technologies developed. In recent years considerable efforts have been made to utilize this program for not only transferring technologies out of the NASA Mission Programs, but also to transfer technologies into the Missions and to leverage the impact of government and private sector innovation.

This paper outlines an approach and the creation of a model that brings together industry, government, and commercialization strategies that when implemented, will increase the probability of successful technology development, successful technology infusion into the Mission Programs, and successful commercialization into the private sector.

This model addresses Technology Readiness Levels (TRL) between TRL 3 and TRL 6 which is typically a gap area that is too low for commercial entities or major programs to actively pursue. This model will advance the TRL to an acceptable level for program and industry to afford large investments toward either commercializing or infusion. The model identifies the following four elements necessary for successful adoption:

- Mission Directorate Technology Need.

This element is the most important element because if there is no technology solution required, there is no need to pursue the development.

- Local Program Manager (Level 2) Buy In or Concurrence.

This element is equally important because it is the program which is funded by the Mission Directorate to execute the overall effort. This Manager must provide written support as well as put resources into the effort. This assures value added and increases the probability of acceptance of the technology if development is successful.

- External Partner Involvement.

This element is done via leverages resources, innovative ideas, and capabilities. This will be the key entity to the commercialization aspects of the effort.

- Agency Technology Transfer Organization Involvement.

This element is essential to the facilitation, strategy development, commercialization planning, and seed funding aspects of the effort. 
In short, the collaborative model for successful technology development, infusion, and commercialization is a function of these four elements. Examples of these successes span over a period of 5 years. 
IAC-06-E5.1.04

Technology Transition a Model for Infusion and Commercialization

\author{
Vernotto C. McMillan \\ Innovative Partnership Program Office \\ Technology Transfer Program Manager \\ Engineering Directorate \\ National Aeronautics and Space Administration \\ Marshall Space Flight Center
}

\begin{abstract}
:
The National Aeronautics and Space Administration has as part of its charter the mission of transferring technologies developed for the space program into the private sector for the purpose of affording back to the American people the economical and improved quality of life benefits associated with the technologies developed. In recent years considerable effort has been made to use this program for not only transitioning technologies out of the NASA Mission Directorate Programs, but also to transfer technologies into the Mission Directorate Programs and leverage the impact of government and private sector innovation. The objective of this paper is to outline an approach and the creation of a model that brings together industry, government, and commercialization strategies. When these elements are integrated, the probability of successful technology development, technology infusion into the Mission Programs, and commercialization into the private sector is increased. This model primarily addresses technology readiness levels between TRL 3 and TRL 6 . This is typically a gap area known as the valley of death. This gap area is too low for commercial entities to invest heavily and not developed enough for major programs to actively pursue. This model has shown promise for increasing the probably of TRL advancement to an acceptable level for NASA programs and/or commercial entities to afford large investments toward either commercialization or infusion.
\end{abstract}

\title{
1.0 Introduction:
}

The National Aeronautics and Space Administration which is headquartered in Washington DC is the Nations premium research and development organization. Its vision is to improve life here, to extend life there, to find life beyond; while its mission is to understand and protect our home planet, to explore the universe and search for life, and to inspire the next generation of explorers (1). Throughout its history, NASA has conducted or funded research that has led to numerous improvements to life here on Earth. NASA Headquarters, provides overall guidance and direction to ten field centers and a variety of installations.

It should be noted that NASA conducts its work in four principle organizations, called Mission Directorates:

- $\quad$ Aeronautics: pioneering and proving new flight technologies that improve our ability to explore and which have practical applications on Earth. 
Exploration Systems: creating new capabilities for affordable, sustainable human and robotic exploration

Science: exploring the Earth, moon, Mars and beyond; charting the best route of discovery; and reaping the benefits of Earth and space exploration for society.

Space Operations: providing critical enabling technologies for much of the rest of NASA through the space shuttle, the international space station and flight support.

The Innovative Partnership Program Office which has under its doctrine the Technology Transfer program ${ }^{1}$, the Small Business Innovative Research Program ${ }^{2}$, the Enterprise Engine $^{3}$ Venture Capitalist program, and project URETIs ${ }^{4}$, is a cross mission support organization which reports to the NASA Associate Administrator. The Innovative Partnerships Program (IPP) is primarily focused on providing leveraged technology for Mission Directorate Programs and Projects through investments and technology partnerships with industry, academia, government agencies and national laboratories. As one of NASA's Mission Support Offices, IPP supports all four Mission Directorate Organizations and has program offices at each of the ten NASA Centers.

\subsection{Mission of the IPPO:}

The mission of the IPPO is to provide leveraged technology for Mission Directorates, Programs, and Projects through investments and technology partnerships with industry, academia, government agencies, and national laboratories. The strategies employed by the IPPO include the following:

Facilitate the development of NASA mission relevant technologies through collaborative partnerships with industry, academia, venture capitalist, and other government agencies.

Perform commercialization planning for Mission Directorate Programs and Projects.

Perform intellectual property management of NASA's IP assets.

\footnotetext{
${ }^{1}$ Technology Transfer Program is a congressionally mandated program designed to tax technology developed at the expense of the tax payer and widely disseminate or spin out into the private sector for the purpose of positively impacting the American economy as well as improving the quality of life. Current efforts include infusion of technology into NASA missions as well.

2 The Small Business Innovative Research Program and Small Business Technology Transfer Program are congressionally mandated programs designed to increase the involvement of small business in the Agency's technical activities and have a positive impact on the American economy.

3 The Enterprise Engine is a program designed to use seed funding for attracting Venture Capital investments in targeted high risk, but payoff technologies that support the Mission Directorate Programs.

${ }^{4}$ Project URETIs is a program consisting of university research teams, competitively selected by NASA, to perform cutting-edge research and technology development and increase the role of universities in NASA's future. University Research, Engineering, and Technology institutes (URETIs) focus on research in nanotechnologies, hypersonics and aeropropulsion, develop enabling capabilities for implementing the Vision for Space Exploration and inspiring the next generation of researchers and explorers.
} 
The results of such a mission if carried out correctly would be an increased range of technology solutions and broadened portfolio, improved cost avoidance, accelerated maturation of technology, and an increased pool of commercial providers with reduced time to market. 


\subsection{Project Background:}

The National Aeronautics and Space Administration has as part of its charter the mission of transitioning technologies developed for the space program into the private sector for the purpose of affording back to the American people the economical and improved quality of life benefits associated with the technologies developed (2). In recent years considerable efforts have been made to utilize this program for not only transferring technologies out of the NASA Mission Programs, but also to infuse technologies into the Missions and leverage the impact of government and private sector innovation. This paper outlines an approach and the creation of a model that brings together industry, government, and commercialization strategies that when implemented increase the probability of successful technology development, successful technology infusion into the Mission Programs, and successful commercialization into the private sector. This model addresses technology readiness levels between TRL 3 and TRL 6. This is typically a gap area that is too low for commercial entities or Major Programs to actively pursue. This model will advance the TRL to an acceptable level for Program and Industry to afford large investments toward either commercializing or infusion into the program. The model identifies four elements necessary for successful adoption. These elements are as follows:

- (A) Mission Directorate Technology Need (this element is the most important element because if there is no technology solution required, there is no need to pursue the development.

(B) Local Program Manager (Level 2) Buy In or Concurrence. This element is equally important because it is the program which is funded by the Mission Directorate to execute the overall effort. This manager must provide written support as well as put resources into the effort. This assures value added and increases the probability of acceptance of the technology if development is successful.

(C) External Partner involvement via leverages resources, innovative ideas, and capabilities. This entity will be key to the commercialization aspects of the effort.

(D) Agency IPPO / Technology Transfer Organization involvement. This element is essential to the facilitation, strategy development, commercialization planning, and seed funding aspects of the effort.

The four elements described above suggest that infusion and commercialization of mission relevant technology is a function of MD technical needs, Local PM buy-in, External partner commitment, and commitment by the cognizant technology transfer organization. In other words, Infusion/Commercialization $=f(A B C D)$. This model and its elements are shown in Figure (1) entitled "Technology Transfer Program Model for Development, Infusion, and Commercialization of Mission Relevant Technology". In short, this collaborative model for successful technology transfer is a function of these four elements. 


\section{Figure (1)}

(Model for Development, Infusion, and Commercialization of Mission Relevant

Technology)

\section{Technology Transfer Program Model for Development, Infusion,} and Commercialization of Mission-Relevant Technology

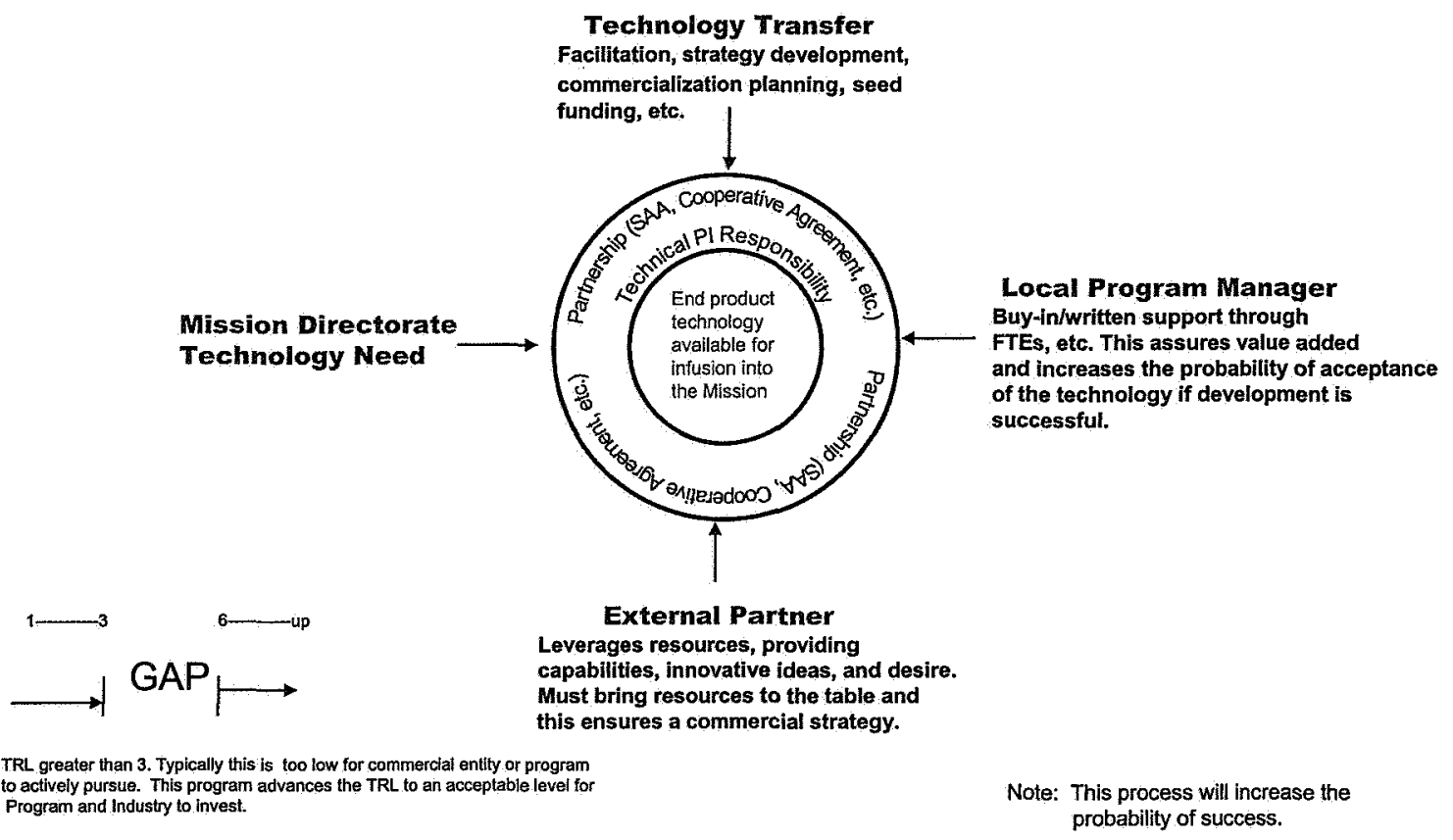

\subsection{Model Development:}

The Marshall Space Flight Center Technology Investment Program (TIP) had been used over a period of 5 years by the IPPO for the purpose of taking NASA Mission Directorate Program/Project technology and through an industry collaboration a viable commercialization plan was developed which led to successful commercialization as well as commercial products. Therefore, TIPs had proven itself as a successful method of taking NASA Mission developed technologies and generating commercial products. However, using a similar model to further technology development that would primarily serve the NASA Mission Directorate Programs would require a change in the primary end game. Although a commercially available product could result, the primary focus would now be to deliver a technology solution to the Mission Directorate Programs.

This new strategy would involve three paradigm shifts. First we would now recognize the MD Program as the primary customer. Second, we would now begin 
with the end in mind. And third we would no longer view infusion and commercialization as two opposite ends of the spectrum. We would now view them as part of a 360 degree cycle that would provide a continuous return on investment. Figure 2 illustrates this philosophy.

\section{FIGURE (2)}

\section{Strategy for Infusion and Commercialization of NASA Technology and Commercialization Planning of NASA Missions}

-Begin with the End in mind -Customer Focus

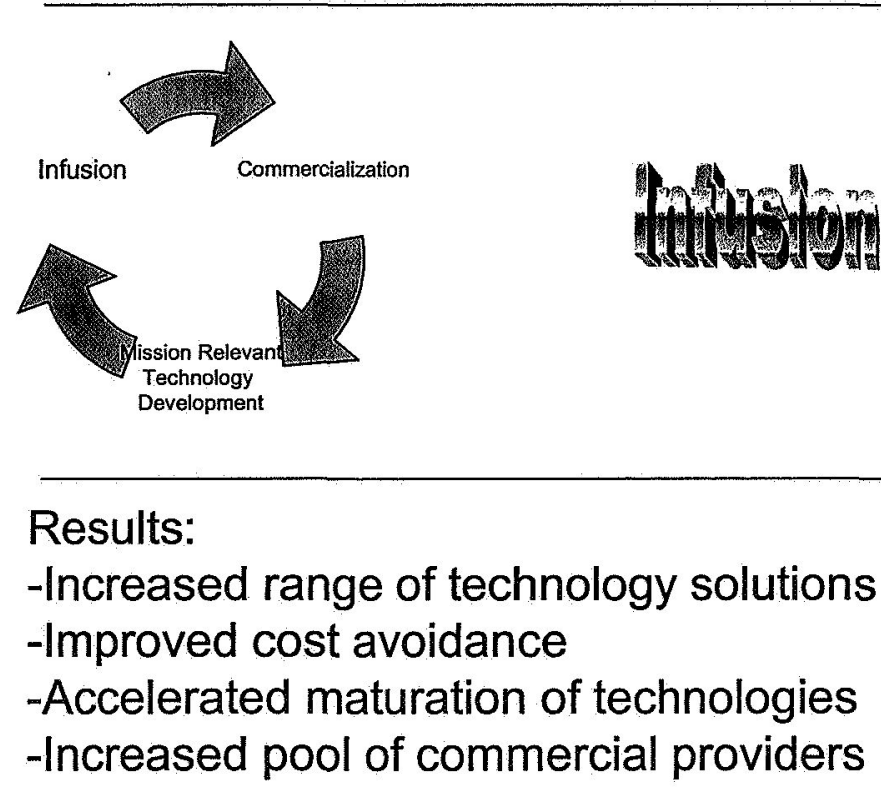

Upon review of TIPs projects that span a five year period (i.e., 2000-2004), it was noted that approximately $10 \%$ of them upon completion had actually been infused into NASA programs and had become commercially available. A review of these projects and the associated factors reveled that they all contained the same four elements. Those elements included the following:

- A primary NASA mission directorate program technical need. This was an imperative to the project success. The MD program needed solutions to their technology gaps in order for the program to succeed.

- A commercial partner that collaborated in the development and put forth a major investment of their own resources for the purpose of being the commercial supplier of the technology. This was a commitment by the commercial partner and was needed for the successful completion of the project. It also ensured that NASA would have a commercial provider should the technology prove successful.

- A local NASA program manager with enough interest in the project and outcome that they invested program resources into the collaboration and followed the developments through fruition. This afforded the $\mathrm{MD}$ program to truly pay attention 
to the developments and learn real time if those developments would impact the critical path of the mission.

- And finally, a technology transfer organization providing seed fund investment, commercialization planning strategy, and project facilitation through out the project life. This was clearly essential to bringing the collaborative elements together.

Although some of these elements were present in all of the TIPs projects, these four elements together were only present in the $10 \%$ that were infused into mission directorate programs. It was also, noted that typically a period of time greater than two years would pass before the TIPs project resulted in a successful infusion or commercialization. Therefore, project funded today would potentially bear fruit starting 3 years from today. This assumes project duration of one year with a successful technology outcome.

Based on these results it was determined that for future TIPs the IPPO would experiment with its technology investment program to determine if Mission Directorate program relevant technology could be systematically advanced to the point of impacting mission critical technology needs. This impact could come in the form of actually proving the technology's value and infusing it into the critical path of the program or learning something that was previously unknown about the particular technology that would render it use less for its intended purpose and thereby affording the program to follow a different technological path to complete the mission.

Therefore, during FY06, TIPs projects were only selected if they met the strict criteria. There were a total of 23 TIPs projects developed during fiscal year 2006 with a total combined investment of approximately $\$ 8$ million dollars. This investment breaks down as follows: The IPPO invested approximately $\$ 1.7$ million, the Mission Directorate Program invested approximately $\$ 3.0$ million dollars, and Industry invested approximately $\$ 3.0$ million dollars.

\subsection{Successful Technology Development Projects}

\subsection{Video Image Stabilization and Registration (VISAR)}

VISAR is an in-house innovation which contained all four elements of the model. The NASA Researcher needed a tool to analyze satellite video and developed a technology that can dramatically improve video images. VISAR stabilizes camera motion in the horizontal and vertical, produces clearer images of moving objects, smoothes jagged edges, enhances still images, and reduces snow. The technology has been used successfully in a criminal case for the NASA Inspector General involving foreign nationals, and it has also been used to analyze footage of the most recent Space Shuttle Columbia launch. NASA's Marshall Space Flight Center and Kennedy Space Center both utilize Intergraph's VideoAnalyst ${ }^{\mathrm{TM}}$ equipment, as well as other federal agencies, including the FBI. 
VISAR has been licensed to Intergraph Government Solutions, and has been incorporated into a video tracking and enhancement system developed by them. During the commercialization process, the speed of $\mathrm{C}++$ processing capability was dramatically sped up. This was an enhancement that was then made available to NASA and incorporated into the software. Intergraph's VideoAnalyst ${ }^{\mathrm{TM}}$ is now a comprehensive, effective, and affordable solution for advanced video analysis and enhancement. It combines capabilities previously found only in high-end broadcast-quality systems with the tools necessary to capture, analyze, enhance, and edit almost any type of video. Figure (3) illustrates the performance of VISAR in tracking the Space Shuttle during launch.

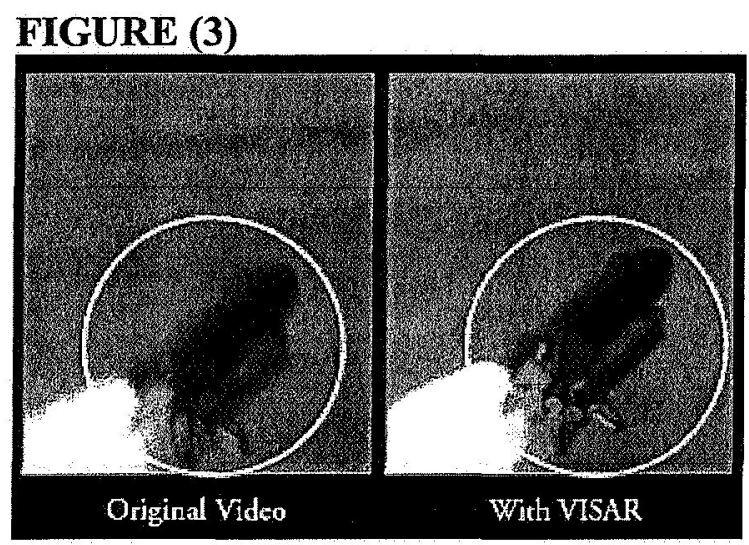

\subsection{Handheld X-RAY Fluorescent Scanners}

The hand held $\mathrm{x}$-ray scanner is another in-house innovation which contained all four elements of the model. This collaboration provided NASA the needed capability of analyzing aluminum alloys composition and was successfully used by the Shuttle Propulsion Office for Return to Flight and is available for use on CLV, CEV and NASA's return mission to the moon. The technology is currently being used in the Space Shuttle Program for failure analysis to evaluate for contamination, corrosion, and material deviations on return-to-flight hardware. The technology is also being proposed for use in regolith (moon dust) simulant process quality control, as well as for use on the lunar surface to determine mineral composition for mining efficiency. This project has also produced an offthe-shelf hardware product that is more affordable for NASA to purchase for its programs.

The commercial partner is KeyMaster Technologies. They have been successful in commercializing the NASA enhanced technology. The commercial product is being called the TRACeR. A major new development for KeyMaster is the utilization of the technology as part of an extensive testing program for highefficiency vacuums and extraction cleaners. In a collaboration with the Carpet \& Rug Institute (CRI), a multi-faceted testing program has been established that will utilize an XRF-detectable soil media that, when applied per the test protocol, can be quantified after each cleaning event to measure the effectiveness of given 
cleaning systems. Equipment that passes these tests, which will be used to set carpet/rug cleaning equipment and chemistry performance standards for the entire \$9B-a-year carpet and rug industry, will receive the Carpet and Rug Institute's Seal of Approval and certification from the Space Foundation. Figure (4) illustrates the hand held unit.

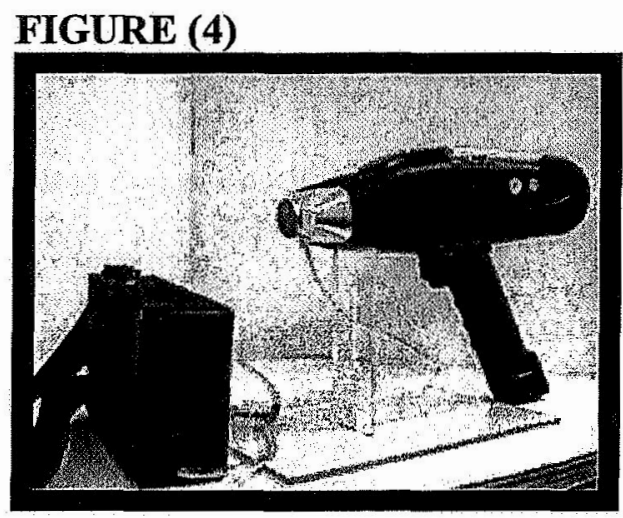

\subsection{Thermal Stir Welding}

Currently being used to support the Space Shuttle Program this technology was a seed fund project which contained all four of the elements. The thermal stir weld technology is planned to be baseline in the Crew Launch Vehicle processing under the Exploration Vision. It is used to join dissimilar materials as well as other applications where friction stir and fusion welding may not be optimum. The external partner Keystone Strategic Enterprises is potentially looking at using the technology to support automotive manufacturing, shipbuilding, storage tank manufacturing and construction applications. Figure (5) illustrates this technology in use.

FIGURE (5)

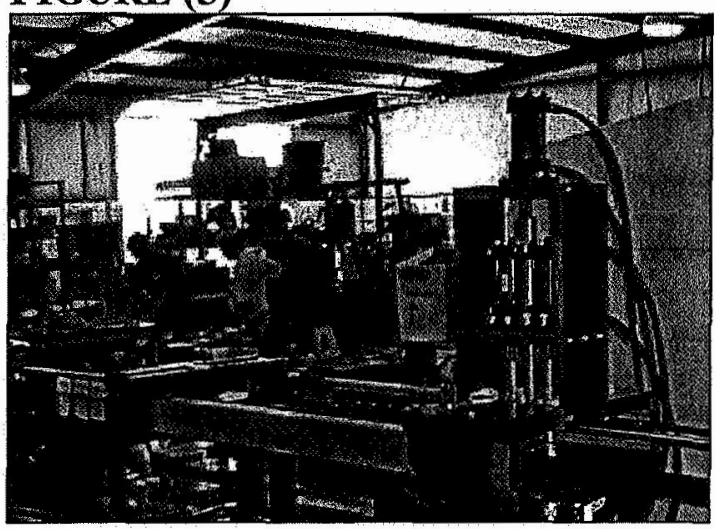




\subsection{Current Technology Development Projects}

During FY06 some 11 new projects were executed following this model. Many of these projects were designed to support the Return to Flight efforts and the Crew Launch Vehicle or Ares One Program. It is anticipated that some of these efforts will in fact lead to critical path decisions relative to these mission successes. These innovative partnerships will leverage existing industry / academic capabilities and technologies to (1) accelerate the achievement of NASA's space exploration goals, (2) enhance economic development through partnerships with industry to use their technologies for NASA missions, and (3) facilitate the later spin-off of the resulting new technologies. The results of these projects will be detailed in a report during FY07.

\subsection{Summary}

The ability to move a new technology from a development laboratory into general use in NASA programs and in industry is of increasing concern as today's economic climate constantly reduces the time available for companies to develop new products and for NASA programs to deliver within budget. This type of technology transition is a difficult and slow process because getting an idea adopted even when it has obvious advantages can be very difficult (3). Many innovations require a lengthy period, often of several years, from the time when they become available to the time when they are widely adopted. Therefore, the common question for many organizations is how to speed up the rate of diffusion or infusion of an innovation. This paper has introduced a model for infusing and commercializing in-house research and development within NASA.

This model was initiated by first viewing the infusion and commercialization processes as a non linear 360 degree system. The principle investigator must evaluate the commercial potential of the respective technology early (i.e., begin with the end in mind) and maintain a clear customer focus in order to increase the potential of success. By engaging the Mission Directorate Program managers and having them endorse the project with program resources we are able to accomplish two things. First a confirmation of the importance of the technological issue and secondly, if the program has resources involved they will actively monitor the outcome. If the research is successful the technology has a greater potential of being adopted into the critical path of the Mission Directorate Program. Next, we collaborate with a commercial partner that is both technically and financially committed to the success of the effort. This is key to a successful commercialization of the technology. This partner may become the technology supplier in the end. Also, this leveraging affords greater expansion of resources and nurtures a collaborative relationship. Finally, a technology transfer organization with commercialization planning expertise and seed funding to assist in the developmental process. In short while this model will not guarantee program or commercial success, it does increase the probability of success for technological innovations between TRL 3 and TRL 6 . 
References:

(1) National Aeronautics and Space Administration, Agency Strategic Plan 2003

(2) National Aeronautics and Space Administration, Space Act of 1958, as amended

(3) M.V. Zelkowitz, Software Engineering Technology Infusion within NASA, August 1996

(4) T. J. Allen, Managing the Flow of Technology, Cambridge MA, MIT Press 1977 